\title{
Zinc Binding to Heliorhodopsin
}

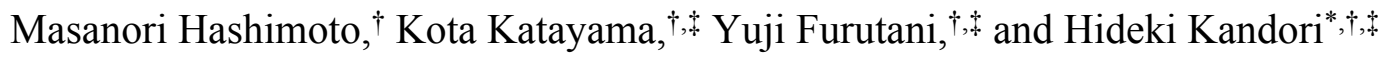 \\ †Department of Life Science and Applied Chemistry, Nagoya Institute of Technology, \\ Showa-ku, Nagoya 466-8555, Japan \\ * OptoBioTechnology Research Center, Nagoya Institute of Technology, Showa-ku, \\ Nagoya 466-8555, Japan
}

Email: kandori@nitech.ac.jp

\section{Methods:}

Sample preparation. TaHeR with an $\mathrm{N}$-terminal $\mathrm{His}_{6}$-tag was prepared as reported previously (1), in which the construct additionally contained a thrombin cleavage site after the $\mathrm{N}$ - terminal $\mathrm{His}_{6}$ tag. Briefly, the proteins were expressed in Escherichia coli strain C43 (DE3), solubilized by $1.0 \%$ DDM in the presence of $300 \mathrm{mM} \mathrm{NaCl}, 5 \mathrm{mM}$ imidazole and $50 \mathrm{mM}$ MES (pH 6.5), and purified by a $\mathrm{Co}^{2+}$-NTA affinity column. His-tagged proteins were eluted with elution buffer $(0.1 \%$ DDM, $300 \mathrm{mM} \mathrm{NaCl}, 50 \mathrm{mM}$ MES, pH 6.0 and $500 \mathrm{mM}$ imidazole), and the collected fractions were dialyzed against a solution containing $100 \mathrm{mM} \mathrm{NaCl}, 0.1 \%$ DDM and $50 \mathrm{mM}$ HEPES (pH 7.0). Detergent in the purified TaHeR was removed by using Bio-Beads (SM-2, Bio-Rad) for ATR-FTIR spectroscopy.

For the $\mathrm{His}_{6}$-tag-free sample, $\mathrm{His}_{6}$-tag was removed by overnight treatment with $10 \mathrm{U} / \mathrm{mg}$ protein of thrombin at $4{ }^{\circ} \mathrm{C}$ after protein purification (2). To remove uncleaved His tag molecules, thrombintreated protein was purified using Micro-spin columns (Thermo Scientific, Waltham, MA, USA) containing Co-NTA resin. The flow-through fraction was used in each experiment.

$\mathrm{HeR} 48 \mathrm{C} 12$ with an $\mathrm{N}$-terminal $\mathrm{His}_{6}$-tag was prepared as reported previously (3)

ATR-FTIR Spectroscopy. Cation-binding to TaHeR was monitored by ATR-FTIR spectroscopy as described previously (4-6), with slight modifications. In ATR-FTIR spectroscopy, rhodopsins are normally reconstituted into lipids. However, we found that the reconstitued sample with a proteinto-lipid molar ratio of 1:20 exhibits significant protein-lipid shrinkage upon binding of divalent cations. Therefore, we did not add lipid in the present study. We removed the detergent with BioBeads (SM-2, Bio-Rad), so that TaHeR molecules are presumably surrounded by native lipids. The protein was placed on the surface of a silicon ATR crystal (Smiths, three internal total reflections) 
and naturally dried. The sample was then rehydrated with the buffer at a flow rate of $0.6 \mathrm{ml} \mathrm{min}^{-1}$, and temperature was maintained at $20^{\circ} \mathrm{C}$ by circulating water. The perfusion buffer is composed of $150 \mathrm{mM} \mathrm{NaCl}$ and $10 \mathrm{mM}$ HEPES-Na, $\mathrm{pH} 7.0$ (buffer A), to which a divalent cation such as $\mathrm{Zn}^{2+}$ was added (buffer B). ATR-FTIR spectra were recorded at $2 \mathrm{~cm}^{-1}$ resolution, using an FTIR spectrometer (Agilent) equipped with a liquid nitrogen-cooled mercury-cadmium-telluride (MCT) detector (an average of 1710 interferograms per $15 \mathrm{~min}$ ). Cation-induced difference spectra were measured by switching buffer A and buffer B. The buffer containing the EDTA/EGTA mixture (buffer W) was perfused after $\mathrm{Zn}^{2+}$ perfusion to complete the removal of $\mathrm{Zn}^{2+}$ in the flow path, before measuring the $\mathrm{Zn}^{2+}$-free form (using a flow of $\mathrm{Zn}^{2+}$-free buffer). The cycling procedure is shown in Figure S1, and the difference spectra were calculated as the average of the presence minus absence spectra of the cation. The spectral contributions of the unbound salt, the protein-lipid swelling/shrinkage, and the water-buffer components were corrected. 


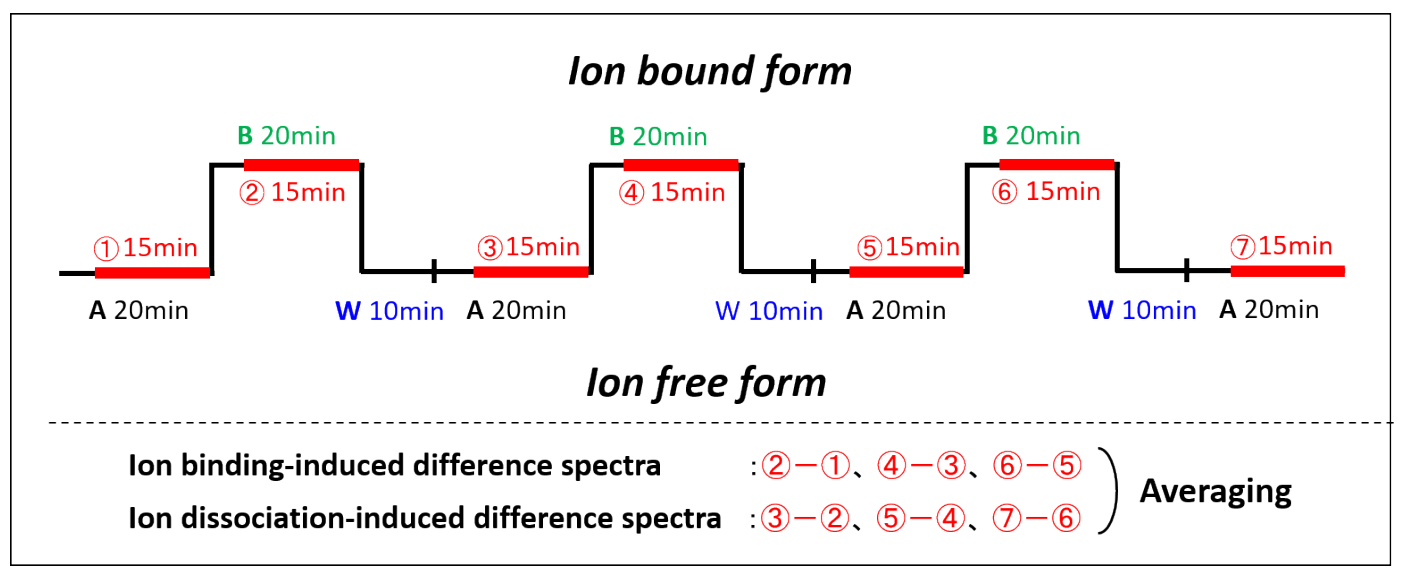

Figure S1. Experimental procedure of ATR-FTIR spectroscopy. $\mathrm{Zn}^{2+}$-induced difference spectra were measured by switching perfusion buffers (10 mM HEPES-Na, $\mathrm{pH}$ 7.0, $150 \mathrm{mM} \mathrm{NaCl}$ ) with (buffer B) or without (buffer A) $\mathrm{ZnCl}_{2}$. The buffer containing the EDTA/EGTA mixture (buffer W) was perfused after $\mathrm{Zn}^{2+}$ perfusion to complete the removal of $\mathrm{Zn}^{2+}$ in the flow path, before measuring the $\mathrm{Zn}^{2+}$-free form (using a flow of $\mathrm{Zn}^{2+}$-free buffer). 


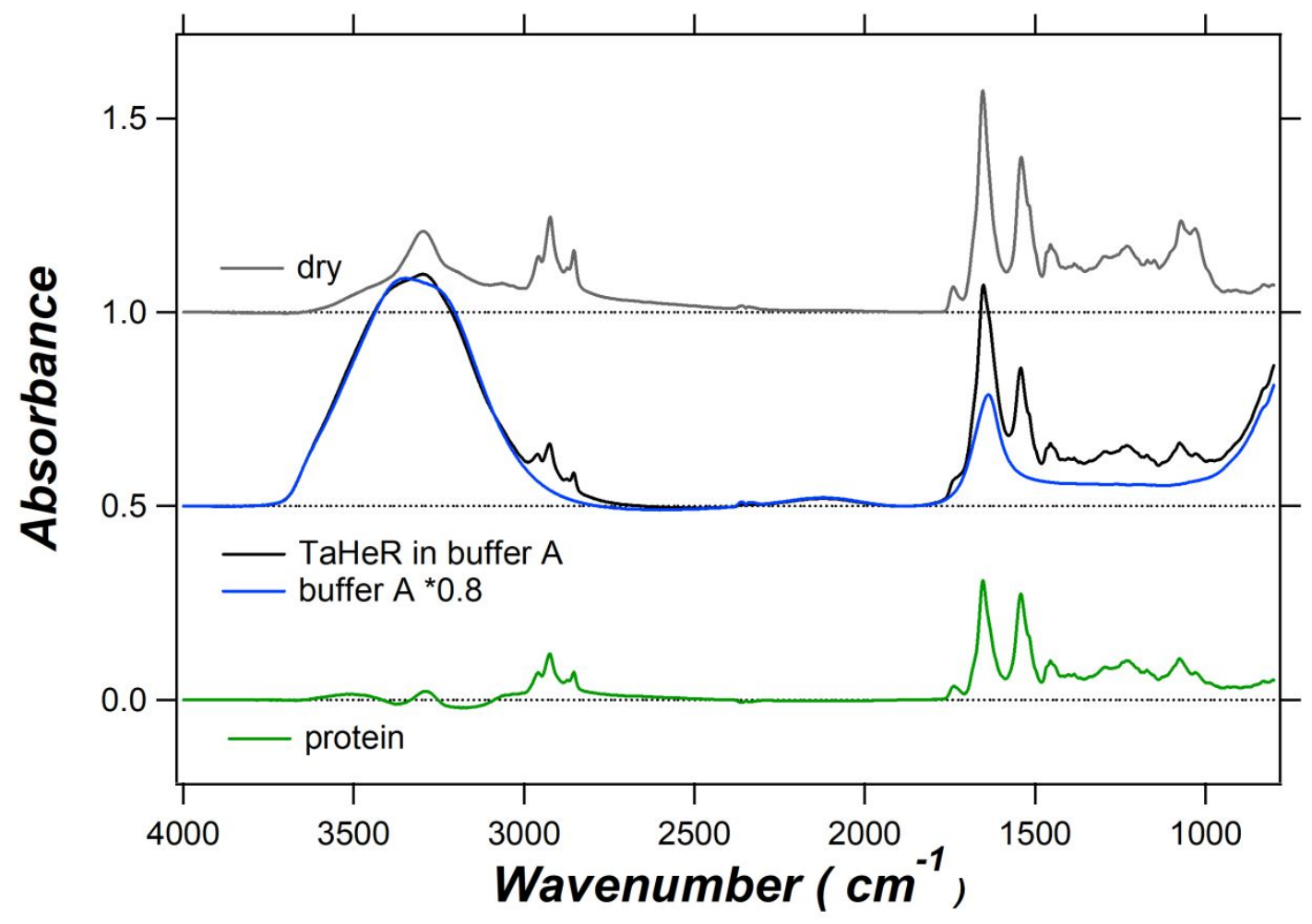

Figure S2. IR absorption spectra of TaHeR. The gray line is the absorption spectrum of the dry film of TaHe. The black line is the absorption spectrum of TaHeR in buffer A. The absorption spectrum of buffer $\mathrm{A}$ is shown as a blue line, after multiplying by 0.8 . The green line, which is the estimated spectrum of TaHeR in buffer A, was obtained by subtracting the blue line from the black line. Both blue and green lines were used for the spectral correction of the obtained difference FTIR spectra of cation binding. 


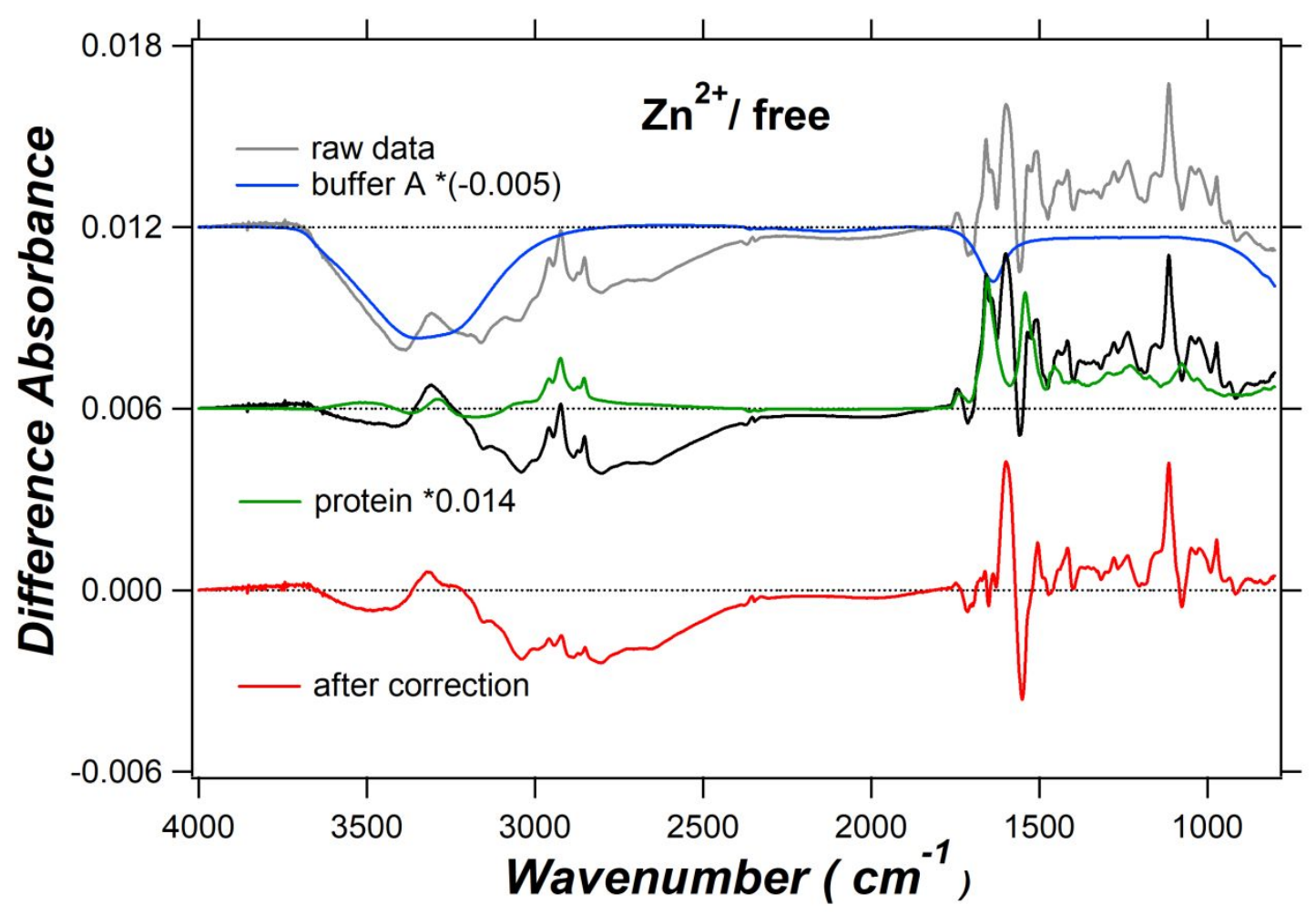

Figure S3. $\mathbf{Z n}^{2+}$ binding induced difference FTIR spectra. Gray line is the raw data of the presence (buffer B) minus absence (buffer A) spectrum of $0.5 \mathrm{mM} \mathrm{Zn}^{2+}$. The broad negative spectral feature at $3700-2500 \mathrm{~cm}^{-1}$ originates from the lowered water absorption, which was corrected by using the spectrum of buffer A after multiplying by -0.005 (blue line). The obtained spectrum (black line) exhibits sharp positive bands at $3000-2800 \mathrm{~cm}^{-1}$, indicating increased absorption of protein and lipid. Therefore, the green line in Figure S2 was subtracted from the black line after multiplying by 0.014 , leading to the final presence minus absence spectrum of $0.5 \mathrm{mM} \mathrm{Zn}^{2+}$ (red line). 


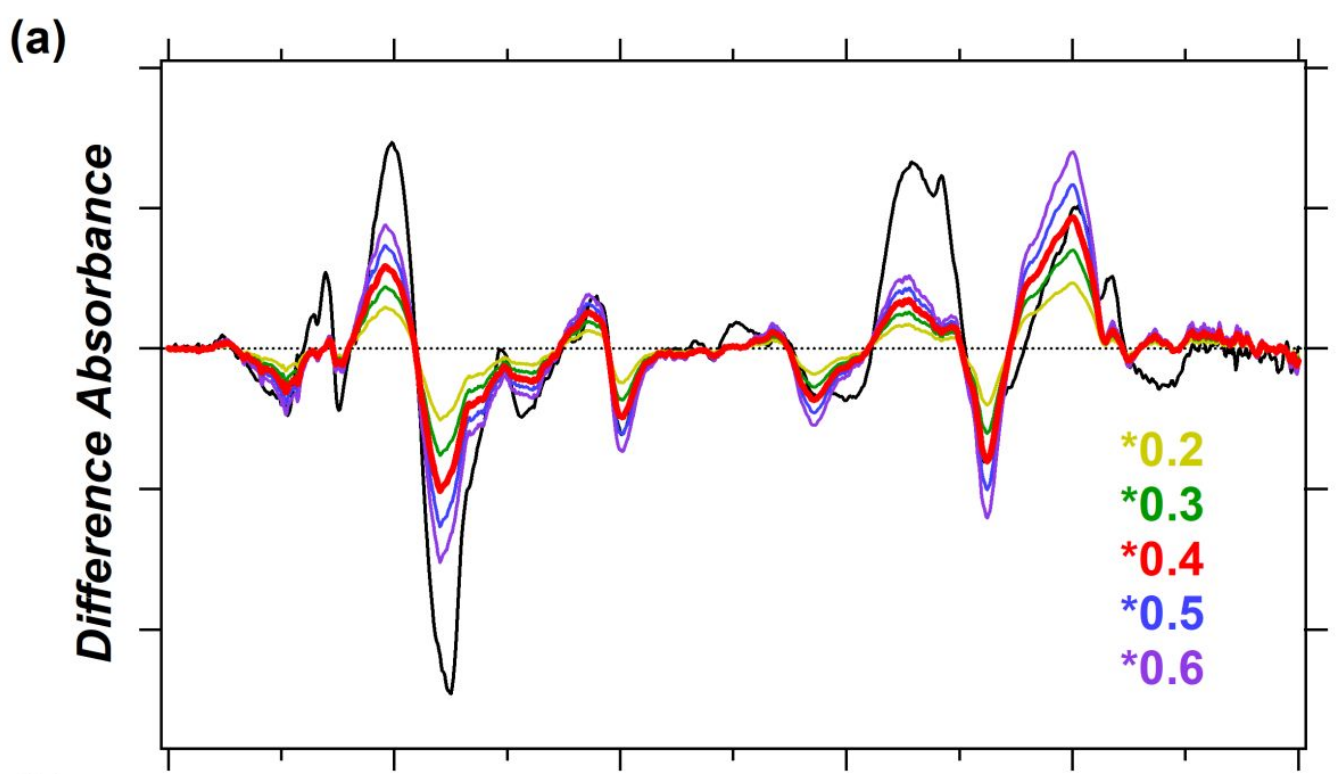

(b)

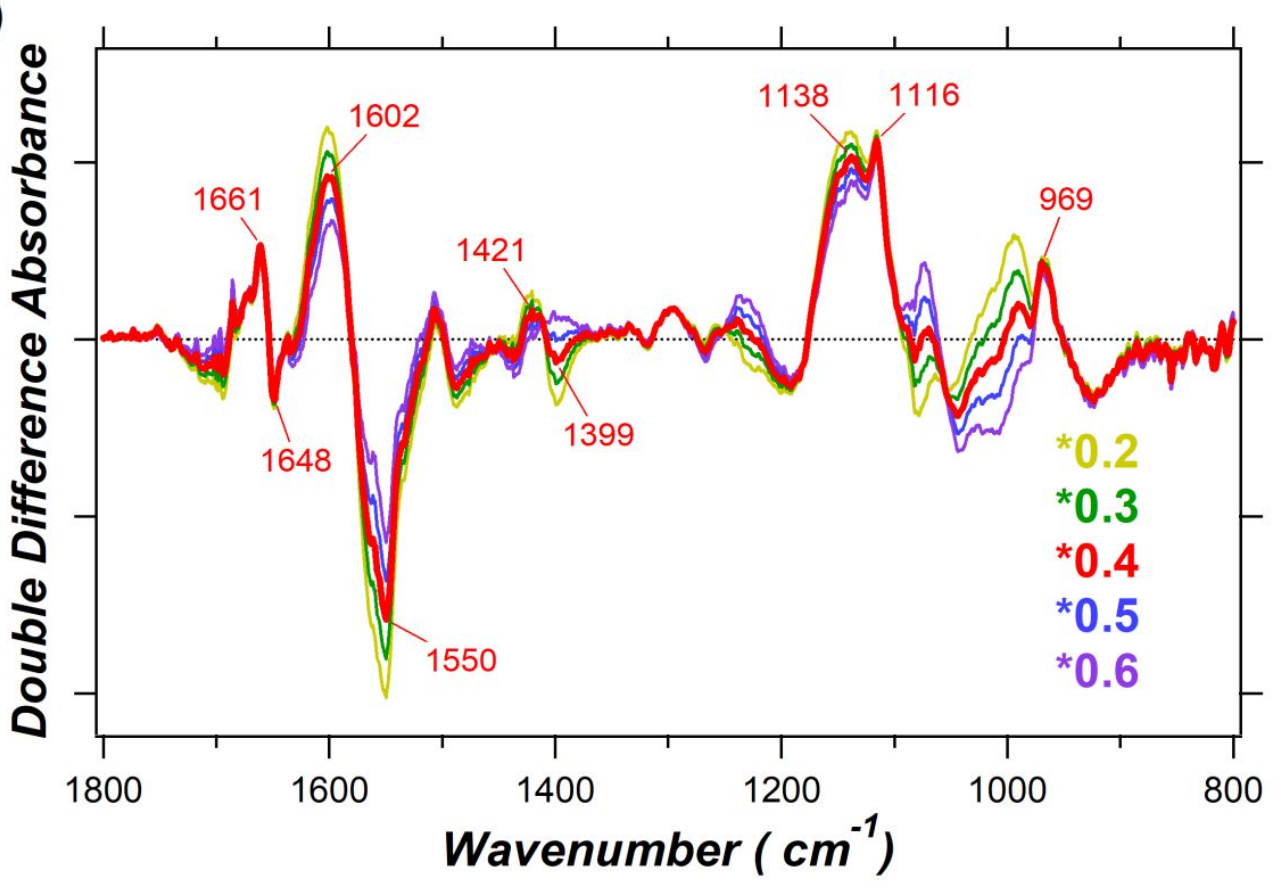

Figure S4. Trial to extract the specific binding of $\mathbf{Z n}^{2+}$ to TaHeR. (a) The black line, the difference spectrum for $0.15 \mathrm{mM} \mathrm{Zn}^{2+}$ (Figure 3a), contains two spectral components with and without helical structural changes at $1660-1645 \mathrm{~cm}^{-1}$, which are regarded as specific and non-specific binding, respectively. The remaining five spectra, the double difference of $5 \mathrm{mM}$ and $1 \mathrm{mM}$ in Figure $3 \mathrm{a}$ after multiplying by 0.2 to 0.6 , originated only from non-specific binding. (b) The subtracted spectra of five colored lines in (a) from the black line, exhibiting a variety of candidates of the pure "difference spectrum for specific binding". From the spectral feature at $1050-1000 \mathrm{~cm}^{-1}$, we propose the red spectrum for specific binding. 
(a)
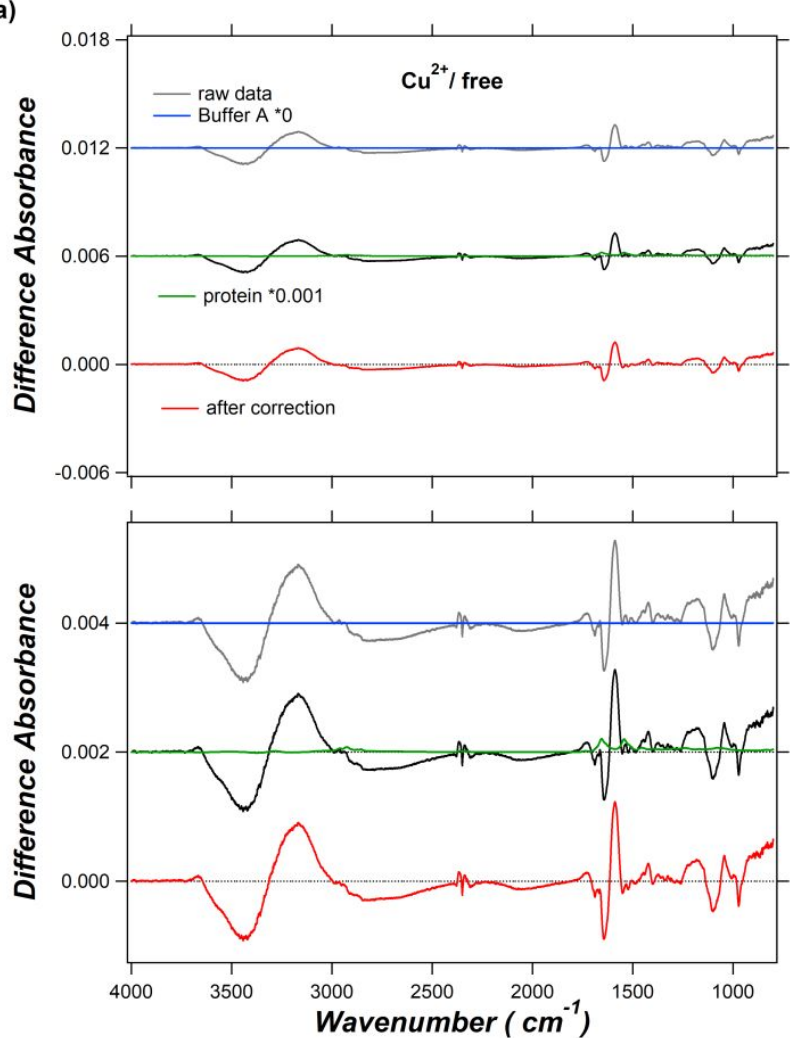

(c)

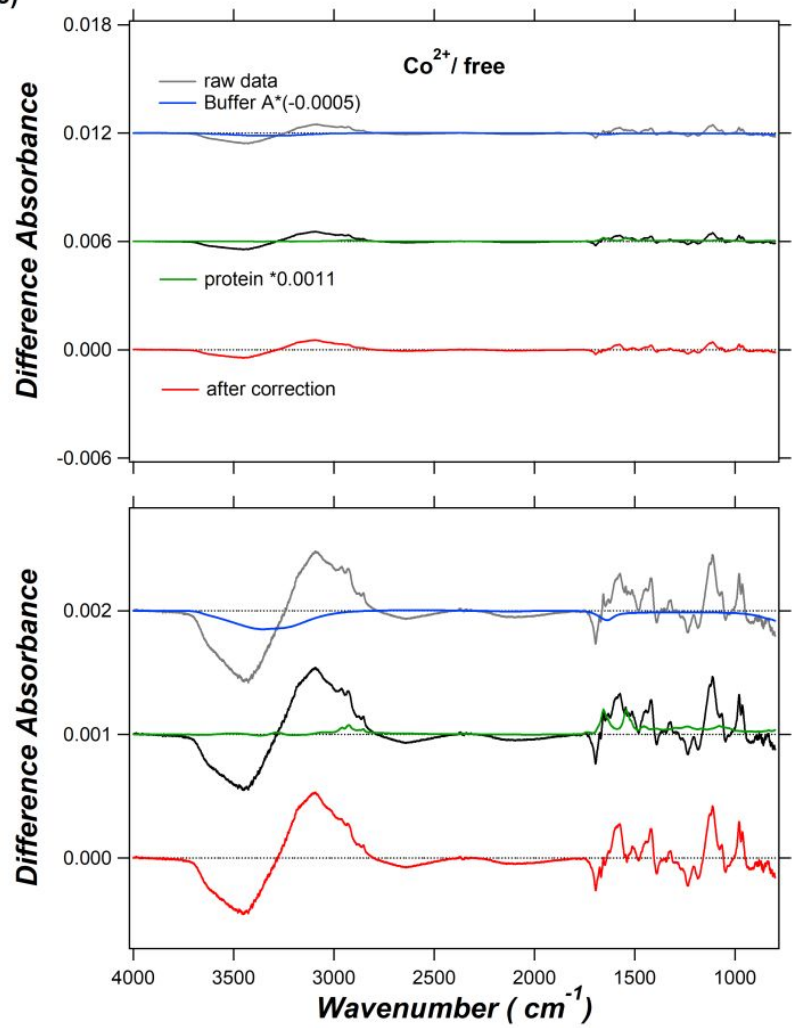

b)
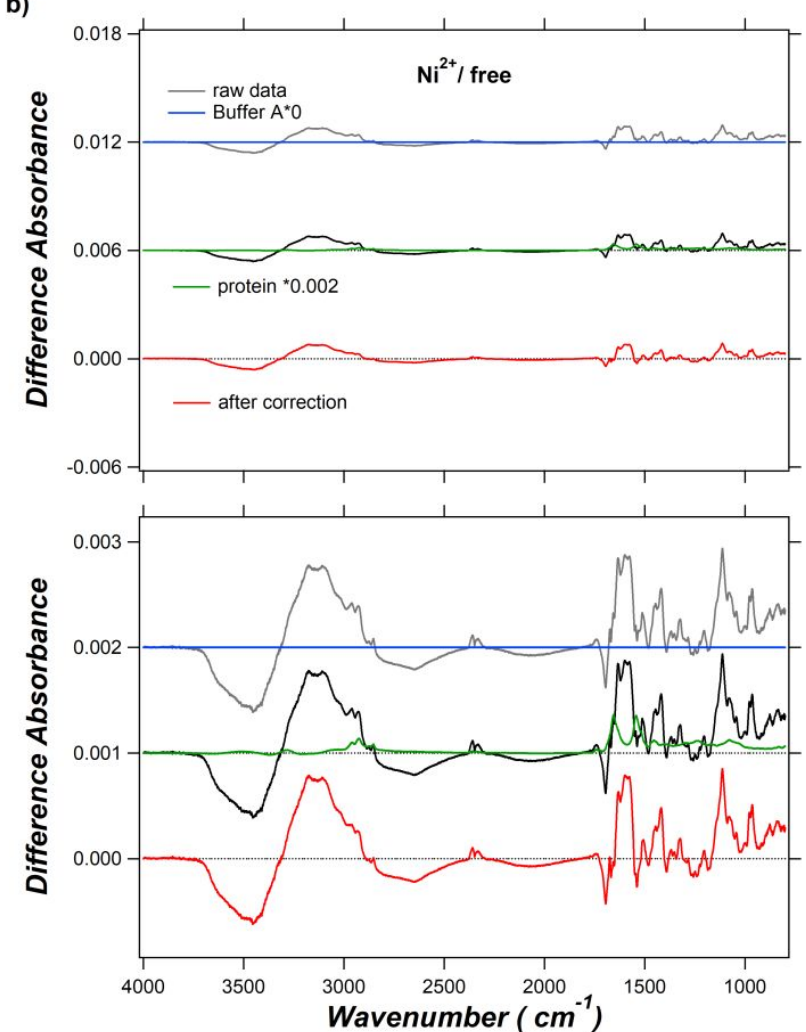

(d)
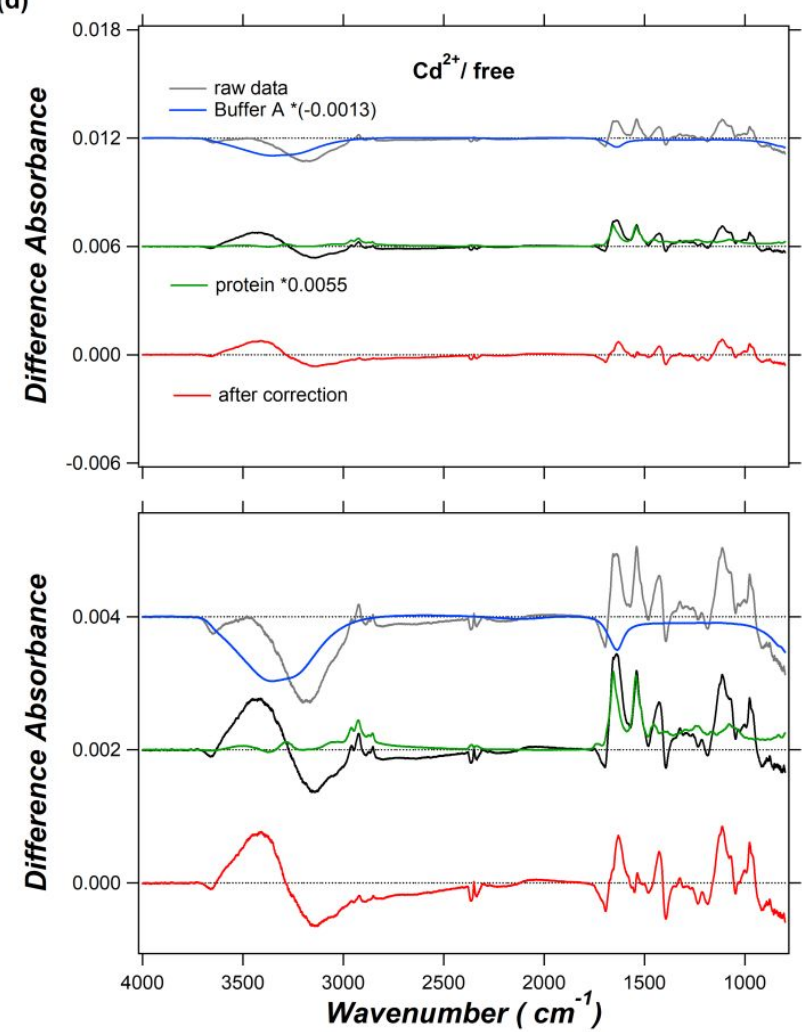
(e)

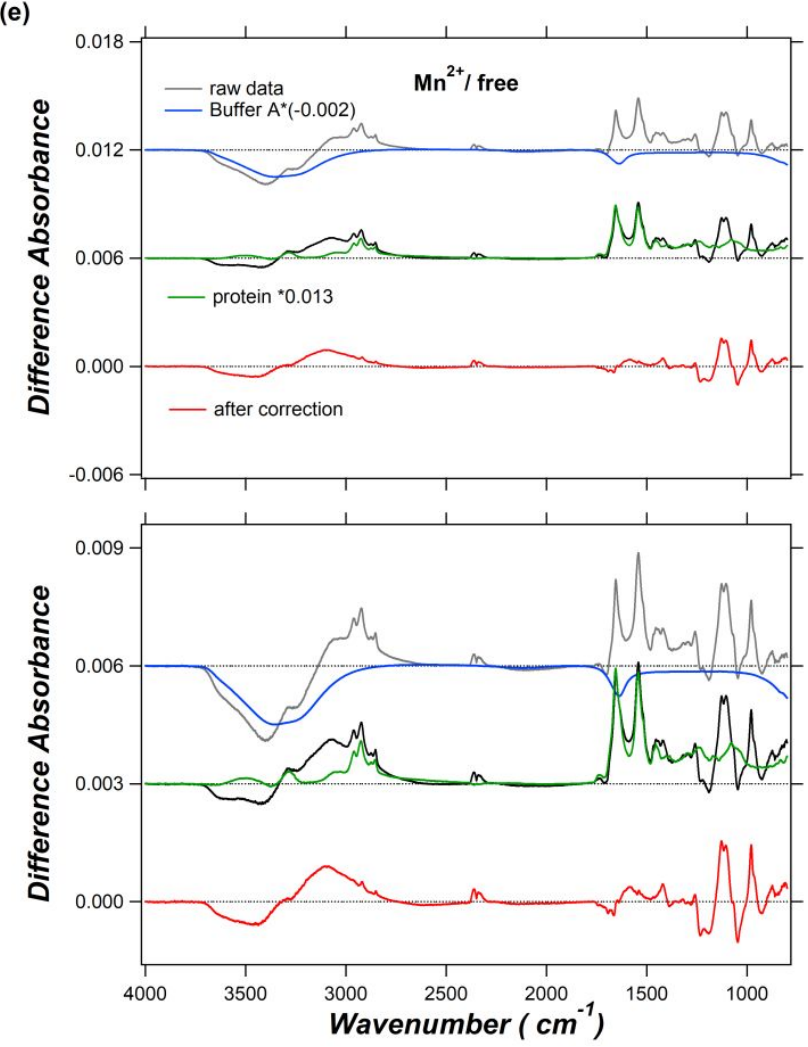

(g)
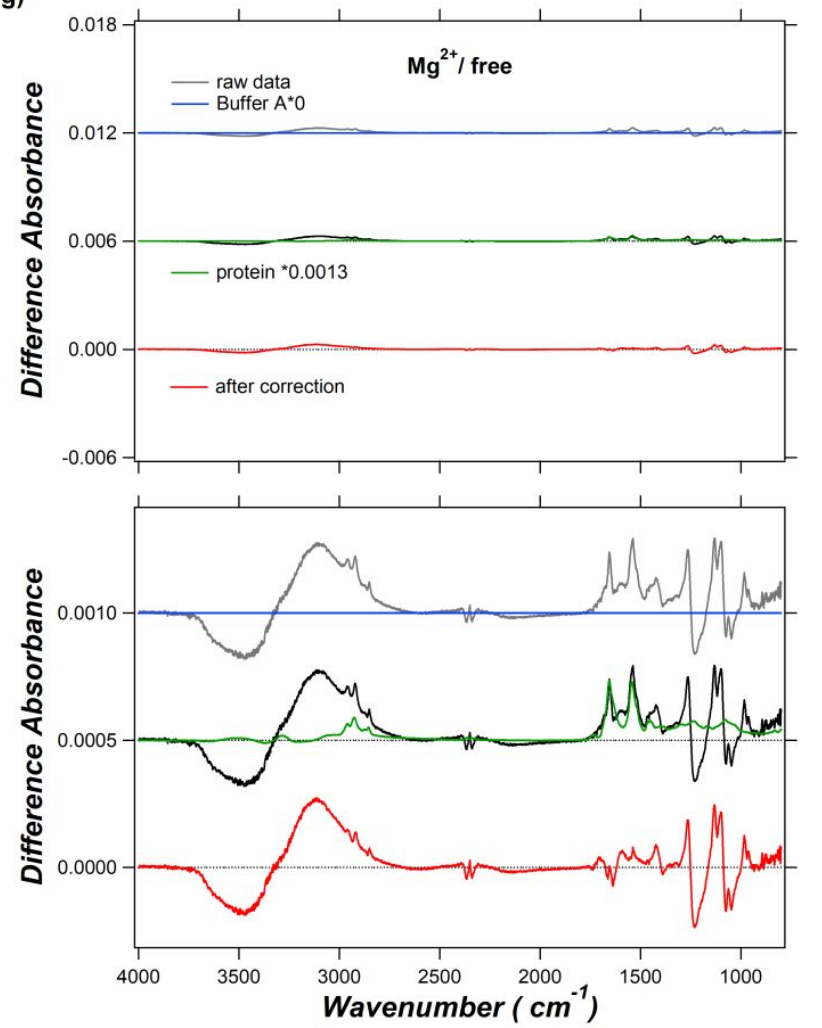

(f)

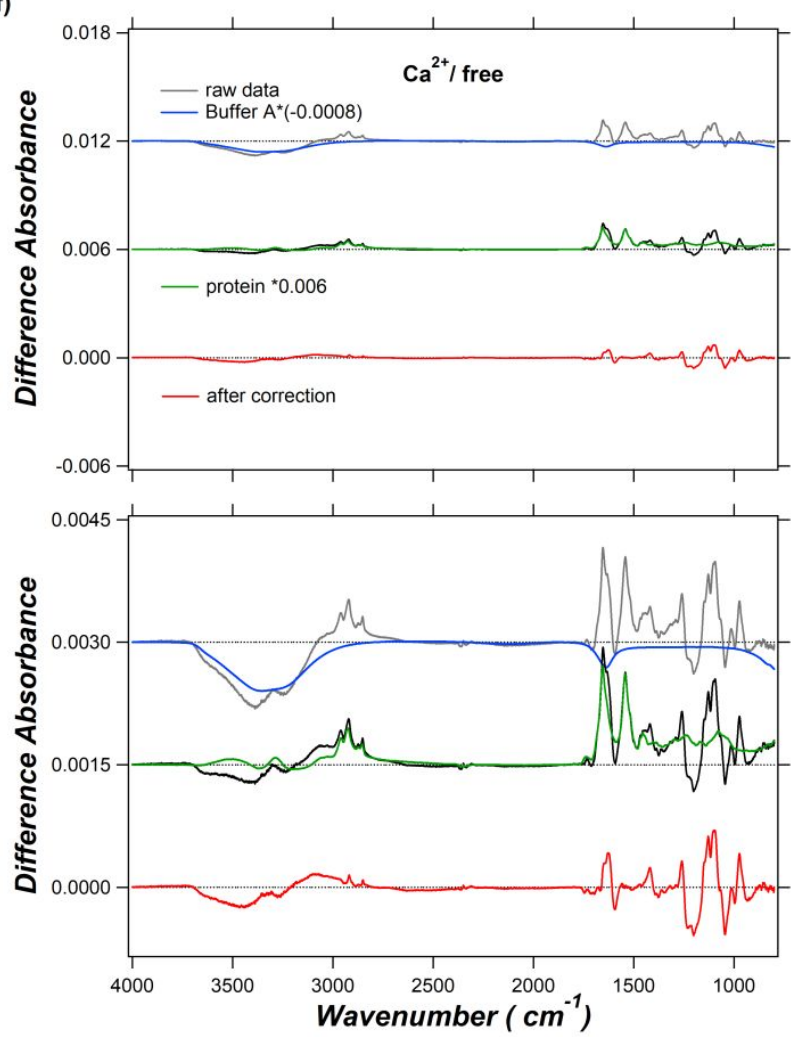

Figure S5. Cation binding induced difference

FTIR spectra. The gray line is the raw data of the presence (buffer B) minus absence (buffer A) spectrum of $0.1 \mathrm{mM} \mathrm{Cu}^{2+}$ (a), $0.5 \mathrm{mM} \mathrm{Ni}^{2+}$ (b), 0.5 $\mathrm{mM} \mathrm{Co}^{2+}$ (c), $0.5 \mathrm{mM} \mathrm{Cd}^{2+}$ (d), $0.5 \mathrm{mM} \mathrm{Mn}^{2+}$ (e), $0.5 \mathrm{mM} \mathrm{Ca}^{2+}(\mathrm{f})$, and $0.5 \mathrm{mM} \mathrm{Mg}^{2+}(\mathrm{g})$, to which a similar spectral correction was adopted using the blue and green lines in Figure S2, as was done for Figure S3. Top panels in (a) to (g) use the same scale for $\mathrm{Zn}^{2+}$ (Figure S3), while the bottom panels enlarge each spectrum. 


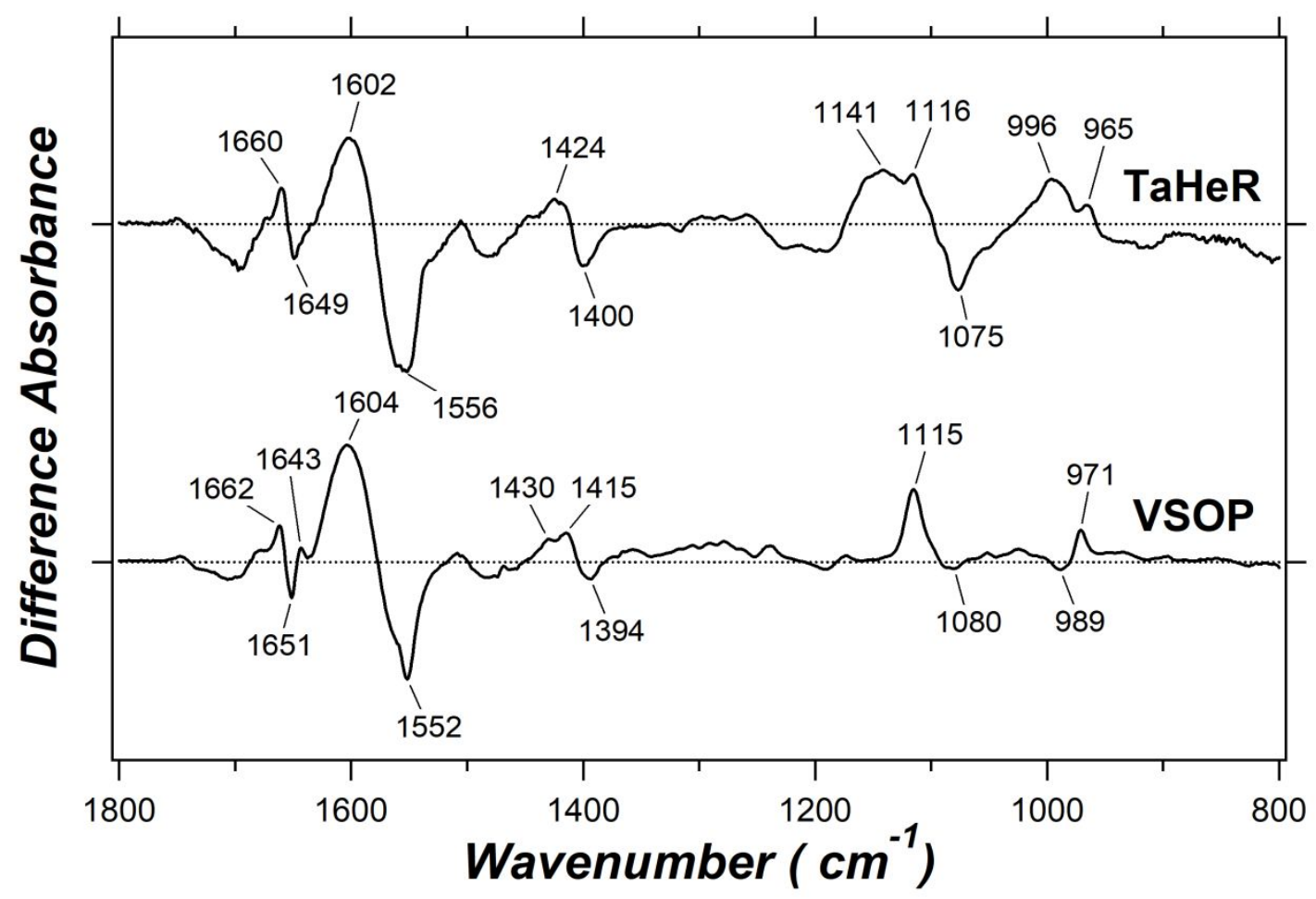

Figure S6. Spectral comparison of $\mathrm{Zn}^{2+}$ binding to TaHeR and VSOP, a voltage-gated proton channel. The spectrum for TaHeR was reproduced from the black solid line in Figure $1 \mathrm{~d}(0.5 \mathrm{mM}$ $\left.\mathrm{Zn}^{2+}\right)$. The spectrum for VSOP was reproduced from Ref. $6\left(0.05 \mathrm{mM} \mathrm{Zn}^{2+}\right)$. The amplitudes of the $\mathrm{y}-$ axis are arbitrary. 


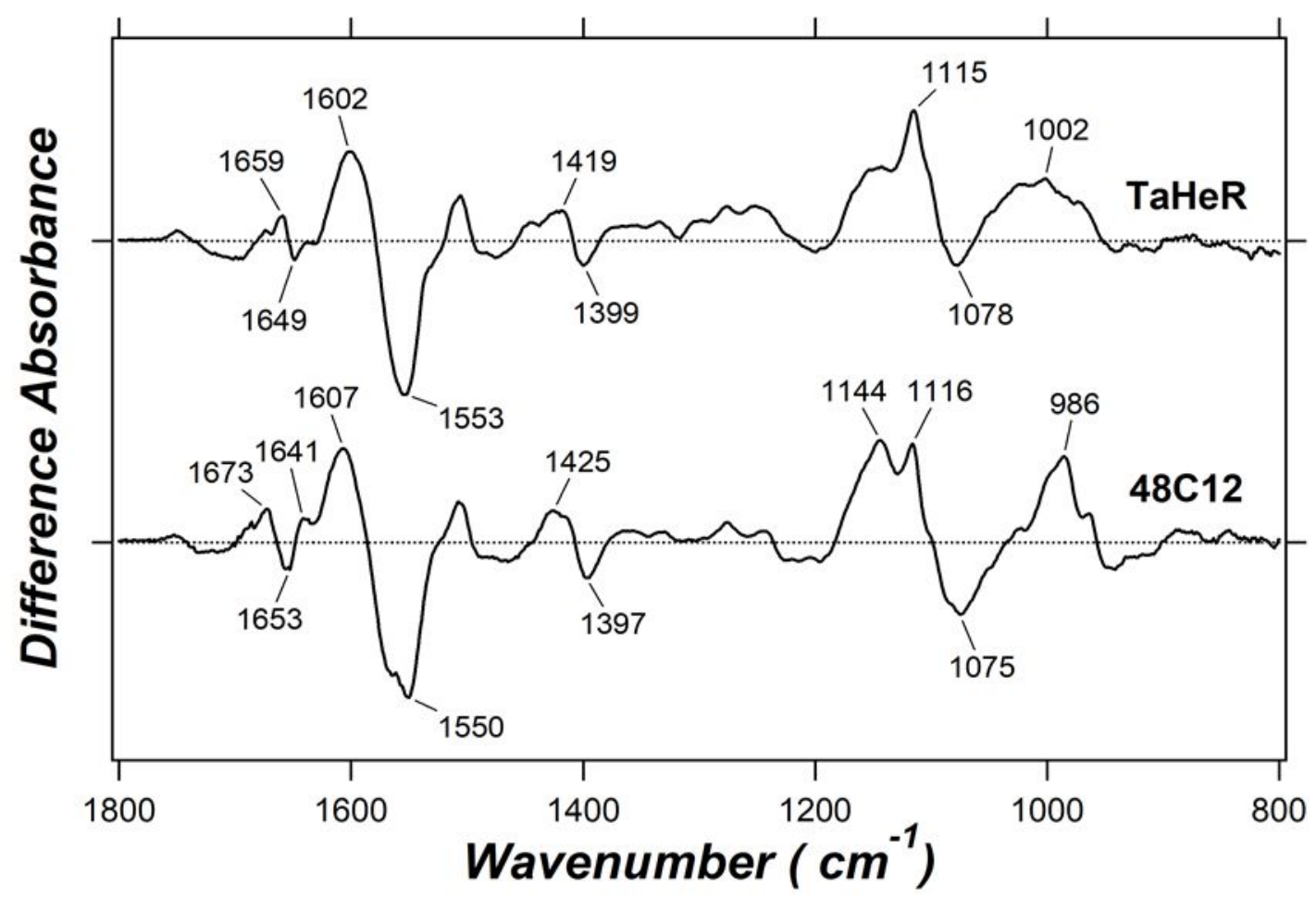

Figure S7. Spectral comparison of $\mathrm{Zn}^{2+}$ binding to TaHeR and HeR 48C12. Presence minus absence spectra of $0.5 \mathrm{mM} \mathrm{Zn^{2+ }}$ for the sample containing His-tag at the $\mathrm{N}$-terminus. The spectrum for TaHeR was reproduced from the black solid line in Figure 1c. 


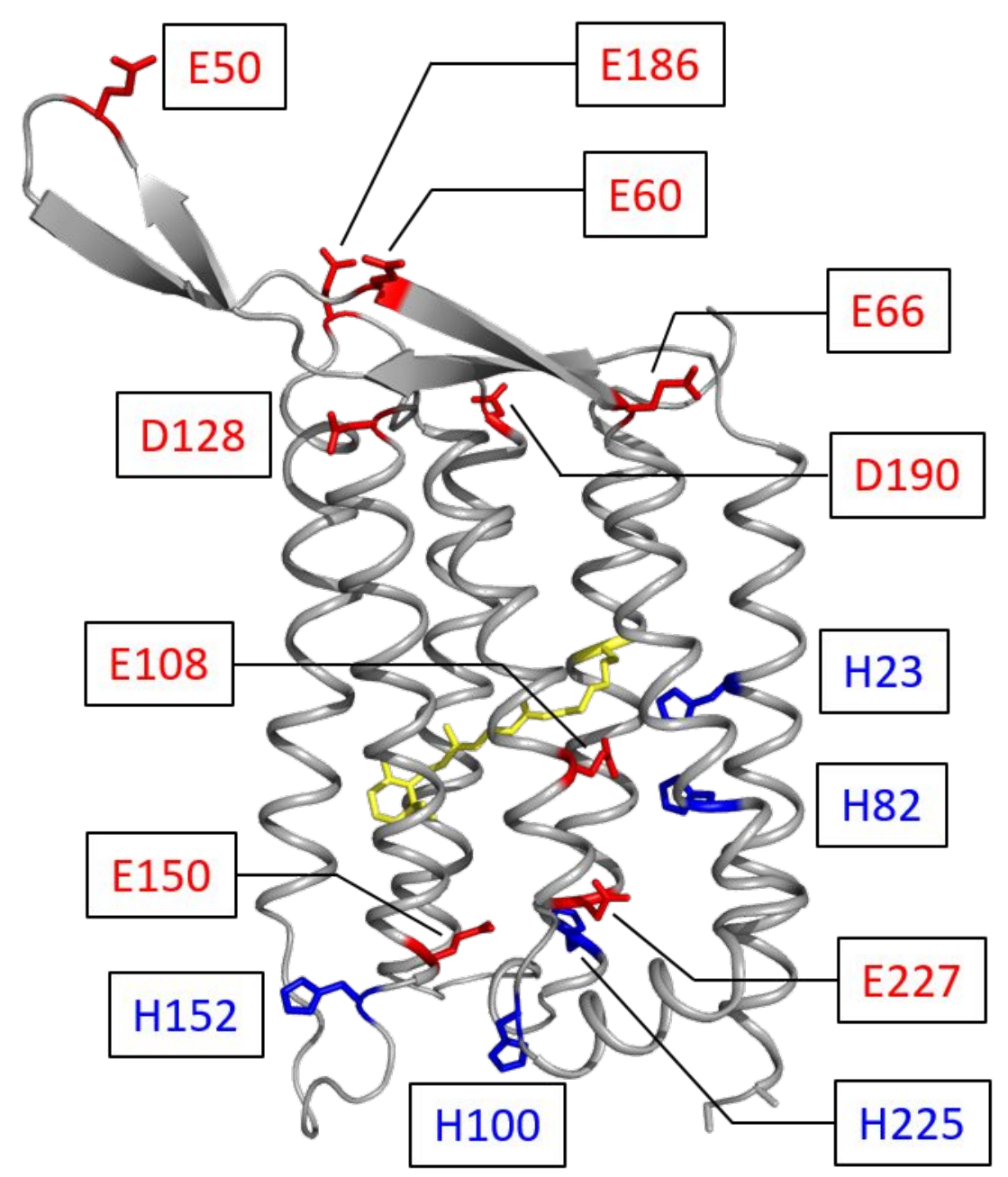

Figure S8. Location of glutamates, aspartates, and histidines in TaHeR. Top and bottom sides correspond to the $\mathrm{C}$-terminal and $\mathrm{N}$-terminal sides that face the extracellular and cytoplasmic region, respectively. 


\section{References}

(1) Shihoya, W.; Inoue, K.; Singh, M.; Konno, M.; Hososhima, S.; Yamashita, K.; Ikeda, K.; Higuchi, A.; Izume, T.; Okazaki, S.; Hashimoto, M.; Mizutori, R.; Tomida, S.; Yamauchi, Y.; Abe-Yoshizumi, R.; Katayama, K.; Tsunoda, S. P.; Shibata, M.; Furutani, Y.; Pushkarev, A.; Béjà, O.; Uchihashi, T.; Kandori, H.; Nureki, O. Crystal structure of heliorhodopsin. Nature 2019, 574, 132-136.

(2) Shibata, M.; Inoue, K.; Ikeda, K.; Konno, M.; Singh, M.; Kataoka, C.; Abe-Yoshizumi, R.; Kandori, H.; Uchihashi, T. Oligomeric states of microbial rhodopsins determined by high-speed atomic force microscopy and circular dichroic spectroscopy. Sci. Rep. 2018, 8, 8262.

(3) Pushkarev, A.; Inoue, K.; Larom, S.; Flores-Uribe, J.; Singh, M.; Konno, M.; Tomida, S.; Ito, S.; Nakamura, R.; Tsunoda, S. P.; Philosof, A.; Sharon, I.; Yutin, N.; Koonin, E. V.; Kandori, H.; Béjà, O. A distinct abundant group of microbial rhodopsins discovered using functional metagenomics. Nature 2018, 558, 595-599.

(4) Furutani, Y.; Murata, T.; Kandori, H. Sodium or lithium ion-binding-induced structural changes in the K-ring of V-ATPase from Enterococcus hirae revealed by ATR-FTIR spectroscopy. J. Am. Chem. Soc. 2011, 133, 2860-2863.

(5) Katayama, K.; Furutani, Y.; Iwaki, M.; Fukuda, T.; Kandori, H. "In situ" observation of the role of chloride ion binding to monkey green sensitive visual pigment by ATR-FTIR spectroscopy. Phys. Chem. Chem. Phys. 2018, 20, 3381-3387.

(6) Iwaki, M.; Takeshita, K.; Kondo, HX.; Kinoshita, K.; Okamura, Y.; Takano, Y.; Nakagawa, A.; Kandori, H. $\mathrm{Zn}^{2+}$-binding to the voltage-gated proton channel Hv1/VSOP. J. Phys. Chem. B 2018, $122,9076-9080$. 